\title{
Stimulasi Critical Thinking Mahasiswa Melalui Pendekatan Concept Mapping-Vignette Pada Mata Kuliah Keperawatan Anak
}

\author{
Windasari Aliarosa $^{1 *}$, Mona Megasari ${ }^{2}$ \\ ${ }^{1}$ Departemen Keperawatan Anak, Prodi D III Keperawatan, STIKes Budi Luhur, Cimahi, Indonesia \\ ${ }^{2}$ Departemen Keperawatan Anak, Prodi Pendidikan Ners, STIKes Budi Luhur, Cimahi, Indonesia \\ *Email Korespondensi: waliarosa@stikesbudiluhurcimahi.ac.id
}

\begin{abstract}
ARTICLE INFO
HOW TO CITED:

Aliarosa, W \& Megasari, M. (2020). Stimulasi Critical Thingking Mahasiswa melalui Pendekatan Concept MappingVignette pada Mata Kuliah Keperawatan Anak. Jurnal Pendidikan Keperawatan Indonesia 6(1), p. 45-56
\end{abstract}

DOI:

10.17509/jpki.v6i1.21551

ARTICLE HISTORY:

Received

November 29, 2019

Revised

March 23, 2020

Accepted

May 29, 2020

Published

June 20, 2020

\begin{abstract}
ABSTRAK
Permasalahan dalam pendidikan keperawatan adalah dibutuhkannya pengembangan strategi pembelajaran yang secara aktual dapat membantu meningkatkan keterampilan critical thinking mahasiswa, khususnya dalam mata kuliah keperawatan anak. Salah satu pendekatan yang dapat diaplikasikan adalah concept mappingvignette. Tujuan penelitian ini adalah untuk mengidentifikasi pengaruh pendekatan concept mapping-vignette dalam stimulasi critical thinking mahasiswa pada mata kuliah keperawatan anak. Penelitian ini menggunakan desain quasi-experiment posttest only with control group. Pengambilan responden menggunakan purposive sampling dengan jumlah responden sebanyak 37 orang yang terbagi menjadi kelompok intervensi sebanyak 19 orang dan kontrol sebanyak 18 orang melalui pemilihan acak. Instrumen yang digunakan dalam penelitian ini adalah California Critical Thinking Skills Test (CCTST). Hasil perhitungan statistik menunjukkan bahwa nilai $p$-value $(0.283)$ lebih besar dari nilai $\alpha(0.05)$ yang menandakan tidak ada pengaruh signifikan pendekatan concept mapping-vignette terhadap stimulasi critical thinking mahasiswa pada mata kuliah keperawatan anak, namun responden pada kelompok intervensi memiliki nilai critical thinking relatif lebih tinggi dibandingkan dengan responden pada kelompok kontrol, khususnya pada item analisis, inferensial, evaluasi, dan deduksi. Sedangkan pada item induksi, responden pada kelompok intervensi memiliki nilai critical thinking yang lebih rendah dari kelompok kontrol. Berdasarkan pada hasil yang didapatkan, pendekatan concept mapping-vignette perlu diaplikasikan sebagai strategi pembelajaran di kelas khususnya pada mata kuliah keperawatan anak dan dapat dikembangkan untuk mata kuliah keperawatan yang lainnya. Penelitian lain perlu dilakukan dengan menggunakan instrumen critical thinking yang lain, dengan jumlah responden yang lebih besar, dan menggunakan desain pretest-posttest with control group.
\end{abstract}

Kata kunci: Concept Mapping, Vignette, Critical thinking, CCTST, Keperawatan Anak

\section{ABSTRACT}

The problem in nursing education is the need to develop learning strategies that can help improve students' critical thinking skills, especially in pediatric nursing course. One approach that can be applied is concept mapping-vignette. The purpose of this study was to identify the effect of the concept mapping-vignette approach in the stimulation of students' critical thinking in child nursing courses. This study was used a quasi-experiment design post-test only with a control group. The respondents were taken by purposive sampling as many as 37 people who are divided into two groups, 19 respondents as intervention group and 18 respondents as control group through 
random selection. The instrument used in this study was the California Critical Thinking Skills Test (CCTST). The results of statistical calculations showed that the p-value is greater than the $\alpha$ value (0.05), which indicates that there is no significant effect of the concept mapping-vignette approach to the stimulation of students' critical thinking in pediatric nursing course, but respondents in the intervention group have relatively higher critical thinking values compared to respondents in the control group, especially in the items of analysis, inference, evaluation, and deduction. Whereas in the induction item, respondents in the intervention group had lower critical thinking values than the control group. Based on the results, the concept mapping-vignette approach needs to be applied as a learning strategy in the classroom especially in pediatric nursing course and can be developed for other nursing courses. Another research needs to conducted using other critical thinking instruments, with a larger number of respondents and using a pretest-posttest with control group design.

Keywords: Concept Mapping, Vignette, Critical thinking, CCTST, Pediatric nursing

\section{PENDAHULUAN}

Salah satu permasalahan dalam pendidikan keperawatan yaitu dibutuhkannya pengembangan strategi pembelajaran yang secara aktual mampu membantu peningkatan kemampuan critical thinking mahasiswa, yang pada akhirnya akan membantu mahasiswa melakukan pertimbangan dan penilaian klinis keperawatan di lahan praktik atau pada saat mereka bekerja sebagai perawat (Riede, P.M., 2015). Critical thinking didefinisikan sebagai proses siklus yang tidak linear dan memungkinkan seseorang untuk membuat keputusan berdasarkan pada apa yang harus diyakininya dan apa yang harus dilakukan dalam konteks tertentu (Aein, F., Aliakbari, F., 2017). Selain itu Scheffer \& Rubenfeld, 2000, dalam Li, Shasha, \& Ye, Xuchun, 2019, dan Facione, 1990 dalam McCormick, K., 2014 menambahkan bahwa kemampuan critical thinking dalam keperawatan mencakup kemampuan interpretasi, analisis, evaluasi, dan inferens, sebagaimana kemampuan menjelaskan bukti-bukti, konseptual, metodologikal, kriteriologikal, ataupun pertimbangan kontekstual, yang kesemuanya mendasari penilaian atas suatu kondisi. Sejalan dengan hal tersebut, critical thinking harus mulai dilatih di tingkat awal di mana mahasiswa mulai mempelajari asuhan keperawatan. Pembelajaran mengenai asuhan keperawatan memerlukan kemampuan critical thinking yang baik sehingga critical thinking menjadi salah satu keterampilan yang paling penting dimiliki oleh mahasiswa agar mahasiswa dapat memberikan asuhan yang berkualitas kepada pasien (Miller, M.L., 2018).
Keperawatan Anak merupakan salah satu mata kuliah keperawatan inti yang terdiri dari Keperawatan Anak 1 dan Keperawatan Anak 2. Mata kuliah Keperawatan Anak 1 adalah mata kuliah keahlian keperawatan yang berfokus pada respon anak dan keluarganya pada setiap tahap perkembangan mulia lahir sampai akhir masa remaja baik dalam keadaan sehat ataupun sakit akut, di masyarakat ataupun dirawat di rumah sakit (AIPNI, 2015). Masalah yang terjadi pada mata kuliah ini adalah tingkat kelulusan mahasiswa yang masih rendah pada penilaian tahap pertama. Hanya $15 \%$ mahasiswa yang mampu memperoleh nilai sempurna (A) dengan rentang nilai $85-100$ dan 25\% mahasiswa memperoleh nilai minimal $(\mathrm{C}+$ dan $\mathrm{C})$ dengan rentang nilai 64-67 (Data Sekunder Biro Administrasi Akademik, 2018). Data hasil belajar ini menunjukkan bahwa secara umum target kemampuan mahasiswa dalam menganalisis dan mengintegrasikan konsep ke dalam asuhan keperawatan kepada anak dan keluarganya belum tercapai. Selain itu, beberapa hasil penelitian menunjukkan bahwa pembelajaran tentang asuhan keperawatan pada pasien anak lebih menantang dibandingkan dengan pasien dewasa. Gamble, A.S., 2017, mengungkapkan sebagian besar mahasiswa memiliki keterbatasan dalam pengalaman pribadi atau paparan pada pasien anak dalam hal komunikasi, interaksi, pengkajian, dan ketentuan yang terkait dengan batasan usia dan perkembangan. Lebih lanjut, karena keterbatasan ini, dosen pembimbing maupun clinical instructor di lapangan juga menghadapi 
stressor untuk membimbing mahasiswa agar dapat mengintegrasikan konsep dan intervensi keperawatan secara tepat pada pasien anak dan keluarganya (Coffey, J.S., 2013 dalam Aliarosa, W., 2014).

Strategi-strategi pembelajaran telah diterapkan dalam mata kuliah ini, diantaranya discovery learning, project based learning, case study, dan diskusi (Aliarosa, W., 2018). Aplikasi dari beberapa strategi pembelajaran ini belum dapat meningkatkan kemampuan critical thinking yang baik pada mahasiswa. Beberapa strategi dapat digunakan untuk meningkatkan critical thinking, diantaranya simulasi (McCormick, K., 2014; Gamble, A.S., 2017; Zarifsanaiey, N., Amini, M., Saadat, F., 2016), problem-based learning (Da Costa, F., Barbosa, A., 2018; Li, S., Ye, X., Chen, W., 2019), high fidelity (Miller, M.L., 2018), dan concept mapping (Aein, F., Aliakbari, F., 2017). Concept mapping menjadi salah satu strategi yang dapat digunakan untuk menstimulasi kemampuan critical thinking mahasiswa. Concept mapping adalah penyusunan grafik yang terstruktur secara hierarki, disajikan dalam dua dimensi dan menunjukkan hubungan antar konsep dan diindikasikan dengan kata-kata penghubung (Novak \& Gowin, 1984 dalam Maldonado, S., 2014). Sedangkan vignette merupakan kasus pendek yang tidak lengkap yang disusun untuk merefleksikan situasi sebenarnya dengan tujuan untuk mendorong diskusi dan memecahkan masalah secara potensial ketika beberapa pilihan solusi ditawarkan (Piryani, R.M., Piryani, S., 2019). Mahasiswa dihadapkan dengan skenario vignette seorang pasien, membacanya, menganalisis, menginterpretasikan data-data dan menentukan respon yang tepat berupa asuhan keperawatan (Bravo, K.S., Pozehl, B., 2016).

Terdapat beberapa penelitian mengenai critical thinking yaitu Aein, F., Aliakbari, F., 2017, yang meneliti tentang concept map sebagai alat pembelajaran untuk meningkatkan critical thinking mahasiswa keperawatan pada mata kuliah keperawatan anak klinis di Iran dengan menggunakan desain penelitian eksperimen dengan kelompok kontrol dan instrumen CCTST. Hasil yang didapatkan menunjukkan bahwa concept mapping dapat digunakan sebagai strategi pembelajaran klinis untuk meningkatkan keterampilan critical thinking mahasiswa. Penelitian lainnya, yaitu penelitian yang dilakukan oleh Gamble, A.S., 2017, tentang penggunaan simulasi sebagai strategi pembelajaran untuk meningkatkan kemampuan critical thinking mahasiswa melalui desain kuasi eksperimental dan instrumen CCTST. Hasil penelitian menunjukkan bahwa kemampuan critical thinking mahasiswa lebih tinggi pada kelompok penelitian integrasi yang menggabungkan simulasi dengan strategi critical thinking. Kedua penelitian tersebut meneliti tentang critical thinking mahasiswa keperawatan dengan menggunakan instrumen CCTST melalui strategi concept mapping dan simulasi. Satu diantaranya dilakukan pada mata kuliah keperawatan anak klinis. Sedangkan untuk penelitian di Indonesia, hanya terdapat sedikit penelitian tentang critical thinking pada mahasiswa keperawatan.

Peneliti mengembangkan penelitian ini berbeda dengan penelitian-penelitian sebelumnya, yaitu dengan menggunakan concept mapping yang didukung dengan adanya vignette pada mata kuliah keperawatan anak dan diberikan kepada mahasiswa keperawatan pada pembelajaran kelas sebelum mereka belajar di klinik pada semester selanjutnya. Penyertaan vignette di setiap pembuatan concept mapping untuk membantu mahasiswa terpapar tentang perawatan pasien anak dan keluarganya di rumah sakit. Hal ini dikarenakan mahasiswa belum memiliki pengalaman merawat anak sakit di rumah sakit. Hal inilah yang menjadikan penelitian ini bersifat baru. Kebaruan ini menjadi dasar perancangan dan pembuatan aplikasi concept-mapping-vignette sebagai sistem yang dapat digunakan mahasiswa untuk meningkatkan keterampilan critical thinking. Tujuan penelitian ini adalah untuk mengidentifikasi pengaruh pendekatan concept mapping-vignette dalam stimulasi critical thinking mahasiswa pada mata kuliah keperawatan anak. 


\section{METODE}

\section{Desain Penelitian}

Penelitian ini menggunakan desain quasiexperiment post-test only with control group.

\section{Populasi dan Sampel}

Populasi dalam penelitian ini adalah semua mahasiswa Program Studi Pendidikan Ners tingkat III yang sedang mendapatkan mata kuliah Keperawatan Anak 1 berjumlah 40 orang. Teknik pengambilan sampel menggunakan purposive sampling, sebanyak 40 orang, dengan kriteria inklusi yaitu mahasiswa yang bersedia menjadi responden penelitian, mahasiswa yang hadir di setiap pertemuan, dan mahasiswa yang mengumpulkan tugas di akhir pertemuan berupa concept-mapping untuk kelompok intervensi dan lembar tugas jawaban vignette untuk kelompok kontrol. Sedangkan kriteria eksklusi diantaranya responden yang mengundurkan diri di tengahtengah proses penelitian. Dari 40 orang dibagi ke dalam 2 kelompok secara acak, yaitu kelompok intervensi dan kelompok kontrol. Selama proses pemberian intervensi, terdapat 2 orang yang tidak memenuhi pertemuan, satu orang dari kelompok intervensi dan satu orang dari kelompok kontrol. Selain itu, ada satu orang dari kelompok kontrol yang tidak mengumpulkan tugas akhir berupa lembar tugas jawaban vignette. Sehingga terdapat tiga orang yang dikeluarkan dari penelitian ini. Pada saat pelaksanaan post-test terdapat 37 responden yang sesuai dengan kriteria inklusi dan eksklusi yang terdiri dari 19 orang kelompok intervensi dan 18 orang kelompok kontrol. Penelitian ini telah melalui proses review etik dari reviewer penelitian institusi di bawah LPPM STIKes Budi Luhur dan telah mendapat persetujuan dengan nomor 001/EC/LPPMSTIKes/III/2019. Informasi terkait penelitian telah diberikan kepada setiap responden untuk menjamin kerahasiaan data-data pribadi. Inform consent secara verbal juga telah diberikan kepada responden. Responden telah diberitahu bahwa penelitian yang dilakukan tidak memungut biaya dan tidak berdampak pada nilai akhir mata kuliah Keperawatan Anak.

\section{Teknik Pengumpulan Data}

Sebelum dilakukan proses penelitian, peneliti telah memberikan penjelasan secara lisan dan tulisan tentang tujuan, manfaat, proses, kebebasan mengikuti dan kerahasiaan data kepada responden dan bila responden telah menyetujui untuk ikut terlibat maka diikuti dengan pengisian dan penandatanganan informed consent oleh responden dan peneliti. Peneliti memberikan empat sesi pembelajaran dengan dua topik di setiap sesinya. Setiap sesi berlangsung selama 2 pertemuan dan masing-masing pertemuan diadakan selama 100 menit. Topik-topik yang diberikan diantaranya 1) sesi pertama, prematuritas dan hiperbilirubinemian, 2) sesi kedua, asma dan bronkopneumonia, 3) sesi ketiga, TBC dan tonsillitis, 4) sesi keempat, GEA dan konstipasi.

Masing-masing responden baik di kelompok intervensi maupun kontrol diberikan modul pembelajaran yang sama yang didalamnya terdapat kasus vignette dan concept mapping secara umum. Dari setiap kasus vignette diberikan $7-10$ poin pertanyaan yang harus dijawab oleh responden. Pada hari pertama di setiap sesi, kelompok intervensi dan kontrol belajar di ruangan yang sama untuk membahas kasus vignette, memahami concept mapping secara umum, dan menjawab pertanyaan. Diikuti hari kedua, kelompok intervensi dan kontrol belajar di ruang yang terpisah, di mana kelompok intervensi belajar untuk mengembangkan concept mapping yang diarahkan sesuai dengan kasus vignette yang ada. Sedangkan pada kelompok kontrol diadakan diskusi, micro teaching, dan pembuatan asuhan keperawatan sesuai dengan kasus vignette. Setelah semua sesi selesai, kelompok intervensi dan kontrol diwajibkan mengumpulkan semua tugas atau hasil pembelajarannya.

Instrumen penelitian yang digunakan dalam penelitian ini adalah California Critical Thinking Skills Test (CCTST). Peneliti menggunakan instrumen atas izin dan konsultasi dengan Insight Assessment sebagai pihak yang mengembangkan dan memiliki hak atas instrumen CCTST. CCTST merupakan instrumen khusus yang digunakan untuk melihat kemampuan critical thinking 
Aliarosa, W \& Megasari, M. | Stimulasi Critical Thingking Mahasiswa melalui Pendekatan...

mahasiswa yang terdiri dari lima item, yaitu analysis, inferensial, evaluasi, induksi, dan deduksi. Insight assessment telah menyediakan instrumen dalam bahasa Indonesia yang telah baku sehingga peneliti tidak perlu melakukan translasi bahasa. Pengambilan data menggunakan instrumen ini dilakukan setelah semua responden mengumpulkan tugas. Responden mengisi 45 soal critical thinking secara online menggunakan android smartphone masing-masing, di ruangan yang tenang selama 45 menit dalam satu kali pertemuan.

\section{Analisis Data}

Perhitungan statistik dilakukan menggunakan software komputer, dengan mencari frekuensi dan persentase untuk melihat gambaran critical thinking mahasiswa pada mata kuliah Keperawatan Anak setelah diberikan pendekatan concept mapping-vignette pada kelompok intervensi dan kontrol. Sedangkan untuk melihat pengaruh pendekatan concept mapping-vignette terhadap stimulasi critical thinking mahasiswa pada mata kuliah Keperawatan Anak menggunakan analisis T-test.

\section{HASIL}

Gambaran Critical Thinking Mahasiswa Pada Mata Kuliah Keperawatan Anak Setelah Diberikan Pendekatan Concept MappingVignette Pada Kelompok Intervensi dan Kontrol

Tabel 1. Distribusi Frekuensi Tingkat Critical Thingking Mahasiswa Kelompok Intervensi dan Kontrol pada Mata Kuliah Keperawatan Anak

\begin{tabular}{|c|c|c|c|c|c|}
\hline \multicolumn{2}{|c|}{ Sub Variabel } & \multicolumn{2}{|c|}{ Kelompok Intervensi } & \multicolumn{2}{|c|}{ Kelompok Kontrol } \\
\hline & & Frekuensi & $\%$ & Frekuensi & $\%$ \\
\hline \multirow[t]{5}{*}{ Keseluruhan } & Tinggi & 0 & 0 & 0 & 0 \\
\hline & Sedang & 6 & 31,6 & 3 & 16,7 \\
\hline & Rendah & 11 & 57,9 & 10 & 55,6 \\
\hline & Tidak dapat dimanifestasikan & 2 & 10,5 & 5 & 27,8 \\
\hline & Total & 19 & 100,0 & 18 & 100,0 \\
\hline \multirow[t]{5}{*}{ Analisis } & Tinggi & 2 & 10,5 & 1 & 5,6 \\
\hline & Sedang & 9 & 47,4 & 7 & 38,9 \\
\hline & Rendah & 0 & 0 & 0 & 0 \\
\hline & Tidak dapat dimanifestasikan & 8 & 42,1 & 10 & 55,6 \\
\hline & Total & 19 & 100,0 & 18 & 100,0 \\
\hline \multirow[t]{5}{*}{ Inferensial } & Tinggi & 0 & 0 & 0 & 0 \\
\hline & Sedang & 5 & 26,3 & 4 & 22,2 \\
\hline & Rendah & 0 & 0 & 0 & 0 \\
\hline & Tidak dapat dimanifestasikan & 14 & 73,7 & 14 & 77,8 \\
\hline & Total & 19 & 100,0 & 18 & 100,0 \\
\hline \multirow[t]{5}{*}{ Evaluasi } & Tinggi & 0 & 0 & 0 & 0 \\
\hline & Sedang & 9 & 47,4 & 5 & 27,8 \\
\hline & Rendah & 0 & 0 & 0 & 0 \\
\hline & Tidak dapat dimanifestasikan & 10 & 52,6 & 13 & 72,2 \\
\hline & Total & 19 & 100,0 & 18 & 100,0 \\
\hline \multirow[t]{5}{*}{ Induksi } & Tinggi & 0 & 0 & 0 & 0 \\
\hline & Sedang & 8 & 42,1 & 9 & 50,0 \\
\hline & Rendah & 0 & 0 & 0 & 0 \\
\hline & Tidak dapat dimanifestasikan & 11 & 57,9 & 9 & 50,0 \\
\hline & Total & 19 & 100,0 & 18 & 100,0 \\
\hline \multirow[t]{5}{*}{ Deduksi } & Tinggi & 0 & 0 & 0 & 0 \\
\hline & Sedang & 8 & 42,1 & 6 & 33,3 \\
\hline & Rendah & 0 & 0 & 0 & 0 \\
\hline & Tidak dapat dimanifestasikan & 11 & 57,9 & 12 & 66,7 \\
\hline & Total & 19 & 100,0 & 18 & 100,0 \\
\hline
\end{tabular}

Sumber: Data Primer, 2019 
Responden pada penelitian ini dibagi ke dalam dua kelompok, yaitu kelompok intervensi sebanyak 19 orang dan kelompok kontrol sebanyak 18 orang. Tabel 1 memaparkan distribusi penyebaran frekuensi, persentase, dan tingkat critical thinking responden pada kelompok kontrol dan intervensi. Secara keseluruhan, pada kelompok intervensi sebanyak $31,6 \%$ berada pada tingkat critical thinking sedang, sedangkan pada kelompok kontrol, 16,7\% responden berada pada tingkat critical thinking sedang. Untuk responden yang berada pada tingkat critical thinking tidak dapat dimanifestasikan, pada kelompok intervensi sebanyak 10,5\%, sedangkan pada kelompok kontrol sebanyak $27,8 \%$.

Pada item analisis, responden yang berada pada tingkat critical analisis tinggi di kelompok intervensi sebanyak 10,5\% dan pada kelompok kontrol sebanyak 5,6\%. Sedangkan sebagian besarnya berada pada tingkat analisis tidak dapat dimanifestasikan, yaitu sebanyak $42,1 \%$ pada kelompok intervensi dan 55,6\% pada kelompok kontrol. Hasil kemampuan inferensial responden menggambarkan bahwa sebanyak 26,3\% responden pada kelompok intervensi berada pada tingkat critical thinking inferensial sedang, dan 22,2\% responden pada kelompok kontrol berada pada tingkat critical thinking inferensial sedang. Sebagian besar responden, 73,7\% pada kelompok intervensi dan $77,8 \%$ pada kelompok kontrol berada pada tingkat critical thinking inferensial tidak dapat dimanifestasikan.

Hasil analisis data pada item evaluasi menunjukkan bahwa responden yang berada pada tingkat critical thinking evaluasi sedang sebanyak $47,4 \%$ pada kelompok intervensi dan $27,8 \%$ pada kelompok kontrol. Sedangkan untuk responden yang berada pada tingkat critical thinking evaluasi tidak dapat dimanifestasikan pada kelompok intervensi sebanyak 52,6\%, sedangkan untuk kelompok kontrol sebanyak $72,2 \%$. Analisis untuk hasil critical thinking pada item induksi memperlihatkan bahwa responden yang berada pada tingkat crtitical thinking induksi sedang pada kelompok intervensi sebanyak $42,1 \%$ dan pada kelompok kontrol sebanyak 50\%. Sedangkan untuk responden yang berada pada tingkat critical thinking induksi tidak dapat dimanifestasikan, sebanyak $57,9 \%$ pada kelompok intervensi dan $50 \%$ berada pada kelompok kontrol.

Item terakhir pada tingkat critical thinking adalah deduksi. Hasil analisis menunjukkan bahwa sebanyak $42,1 \%$ responden pada kelompok intervensi dan 33,3\% responden pada kelompok kontrol berada pada tingkat critical thinking deduksi sedang. Selain itu, sebanyak $57,9 \%$ responden pada kelompok intervensi dan 66,7\% responden pada kelompok kontrol berada pada tingkat critical thinking tidak dapat dimanifestasikan.

\section{Pengaruh Pendekatan Concept Mapping- Vignette Terhadap Stimulasi Critical Thinking Mahasiswa pada Mata Kuliah Keperawatan Anak}

Tabel 2. Pengaruh Pendekatan Concept Mapping-Vignette Terhadap Stimulasi Critical Thinking Mahasiswa Pada Mata Kuliah Keperawatan Anak

\begin{tabular}{lccc}
\hline \multirow{2}{*}{ Critical Thinking } & \multicolumn{2}{c}{ Mean } & p-Value \\
\cline { 2 - 3 } & Intervensi & Kontrol & \\
$\begin{array}{l}\text { Keseluruhan } \\
\text { (Overall) }\end{array}$ & 10,32 & 9,28 & 0,283 \\
\hline
\end{tabular}

Sumber: Data Primer, 2019

Hasil perhitungan statistik pada Tabel 2 menunjukkan bahwa nilai $p$-Value lebih besar dari nilai $\alpha(0.05)$, hal ini menandakan bila secara umum tidak ada pengaruh pendekatan concept mappingvignette terhadap stimulasi critical thinking mahasiswa pada mata kuliah Keperawatan Anak.

\section{PEMBAHASAN}

Gambaran Critical Thinking Mahasiswa Pada Mata Kuliah Keperawatan Anak Setelah Diberikan Pendekatan Concept MappingVignette Pada Kelompok Intervensi dan Kontrol

Nilai keseluruhan merupakan persentase jawaban benar dari pertanyaan CCTST untuk melihat lima item keterampilan critical thinking mahasiswa yang meliputi analisis, inferensial, evaluasi, induksi, dan deduksi (Riede, P.M., 2015). 
Nilai keseluruhan (overall) menggambarkan kemampuan keseluruhan mahasiswa dalam menggunakan alasan/rasional untuk memberikan penilaian reflektif tentang apa yang dipercayai dan apa yang harus dilakukan. Untuk mencapai hasil keseluruhan yang baik, mahasiswa harus mampu untuk focus serta mengintegrasikan keterampilan dalam membuat alasan, yang terdiri dari keterampilan analisis, interpretasi, inferensial, evaluasi, penjelasan, induksi, dan deduksi. Sehingga hasil keseluruhan memprediksikan kapasitas keberhasilan dalam lingkungan pendidikan yang mana seringkali mahasiswa harus mengambil keputusan dan memecahkan masalah (Insight Assessment, 2019). Hasil rendah yang didapatkan oleh mahasiswa dalam penelitian ini dapat disebabkan karena mahasiswa tidak hati-hati dalam membaca soal dan jawabannya. Hal ini sesuai dengan yang diungkapkan oleh Broadhead, J.,2016, bahwa mahasiswa memiliki motivasi yang kurang untuk menjawab keseluruhan tes dengan akurat setelah mereka mengetahui bahwa tes yang diberikan tidak akan berpengaruh terhadap nilai akhir mata kuliah sehingga mereka terdistraksi dan terburu-buru ketika menyelesaikan tes CCTST.

Analisis dalam critical thinking merupakan proses kognitif yang dicapai melalui pengelompokan data-data dalam sebuah situasi dan menyusunnya menurut prioritas, memeriksa keterkaitan data satu sama lainnya sampai pada membuat keputusan dan penilaian berdasarkan pada data-data tersebut (Facione, 1990 dalam Riede, P.M., 2015). Kemampuan analitik ini harus didukung dengan kemampuan interpretasi yang baik, sehingga mahasiswa dapat memilih pilihan jawaban yang tepat. Kegiatan menganalisis membutuhkan pengalaman dari individu, khususnya mahasiswa. Mahasiswa dalam penelitian ini belum pernah mendapatkan paparan secara langsung kepada pasien anak dan pemberian kasus-kasus anak harian menggunakan concept map dan vignetee merupakan proses pembelajaran yang baru pertama kali dilakukan. Carbogim, F.C., Barbosa, A.C., Oliviera, L.B., 2018, menjelaskan bahwa keterampilan menganalisis membuat individu dapat mengidentifikasi hubungan inferensial dan menguraikannya untuk menyusun bagian-bagian yang terdapat dalam konteks (pertanyaan), di mana diperlukan pengalaman dalam menilai atau kebiasaan untuk melihat kekompleksan suatu masalah dan berusaha untuk menentukan keputusan yang tepat.

Keterampilan analitik memampukan seseorang untuk mengidentifikasi asumsi, alasan dan tuntutan, serta untuk mengkaji bagaimana mereka berinteraksi dalam membentuk suatu argumen. Selain itu, kemampuan analisis juga digunakan untuk mengumpulkan informasi dari bagan, grafik, diagram, wawancara, dan dokumendokumen. Individu dengan keterampilan analitik yang kuat dapat mengikuti pola dan detail. Mereka dapat mengidentifikasi elemen-elemen situasi dan menentukan bagaimana elemen-elemen ini dapat berinteraksi (Aien, F., Aliakbari, F., 2017; Insight Assessment, 2019).

Dari hasil penelitian, walaupun tidak tampak perbedaan yang signifikan antara kelompok intervensi dan kelompok kontrol, namun pada kelompok intervensi jumlah mahasiswa dengan tingkat critical analisis tinggi lebih banyak daripada kelompok kontrol. Sedangkan sisa responden baik dari kelompok intervensi maupun kontrol berada di tingkat analisis tidak dapat dimanifestasikan, di mana jumlah responden pada kelompok kontrol dengan tingkat analisis tidak dapat dimanifestasikan lebih banyak dari kelompok intervensi. Mayoritas responden baik dari kelompok intervensi maupun dari kelompok kontrol masih berada pada tingkat analisis yang tidak dapat dimanifestasikan. Hal ini menunjukkan bahwa hanya sedikit mahasiswa yang sudah dapat mengumpulkan informasi-informasi, berupa data yang terdapat pada item pertanyaan analisis, dan mengkaitkannya dengan dampak atau efek yang terjadi pada sebuah situasi. Hasil ini menunjukkan kesamaan dengan hasil penelitian Aien, F., Aliakbari, F., 2017, di mana nilai keterampilan analitik pada kelompok intervensi lebih tinggi daripada kelompok kontrol dengan menggunakan concept mapping.

Proses keperawatan mengarahkan mahasiswa untuk dapat mengidentifikasi aspek 
bio-psiko-sosial pasien dan menentukan bagaimana ketiga aspek ini berinteraksi sehingga dapat mempengaruhi status kesehatan pasien dan juga keluarganya. Melalui concept mappingvignette, mahasiswa berusaha untuk mengerti hubungan antara data pasien, proses asuhan keperawatan, interaksi dan hubungan antara tanda dan gejala, data diagnostik, dan juga pengobatan yang didapatkan. Menurut Aien, F., Aliakbari, F., 2017, penggunaan concept map lebih dapat meningkatkan kemampuan keterampilan analitik mahasiswa dibandingkan dengan penyampaian kasus dalam asuhan keperawatan tradisional, sebab proses tradisional tidak selalu dapat membuat gambaran holistik tentang kebutuhan pasien dan hubungan di antara data-data pasien. Sebaliknya, dengan concept mapping dan vignette mahasiswa dapat membuat gambaran utuh tentang hubungan antara kondisi fisiologis, patofisiologis, dan psikologis serta interaksi-interaksinya dalam bentuk yang konkrit. Proses ini membantu meningkatkan kualitas analisis mahasiswa (Schuster, 2012; Nirmala dan Shakuntala, 2011, dalam Aien, F., Aliakbari, F., 2017).

Keterampilan induksi digunakan ketika individu menentukan inferensial/simpulan tentang apa yang dipikirkannya mungkin saja benar berdasarkan pada analogi, studi kasus, pengalaman sebelumnya, analisis statistik, simulasi, hipotesis, dan pola yang dikenali dalam suatu objek/peristiwa/pengalaman, dan perilaku. Namun, hal-hal tersebut mungkin saja salah meskipun bukti-bukti yang dimiliki tidak berubah. Alasan induktif inilah yang dapat memberikan kepercayaan dasar dalam membuat keputusan bagaimana harus bertindak (Insight Asessment, 2019). Menurut Facione, 2009, dalam Aien, F., Aliakbari, F., 2017, alasan induksi membantu individu dalam mengisolasi penyebab penyakit atau terbentuknya teori untuk menjelaskan kembali tentang hubungan-hubungan antara tanda dan gejala yang muncul. Sedangkan keterampilan evaluasi memampukan mahasiswa untuk mengkaji kredibilitas sumber-sumber informasi.

Keterampilan evaluasi ini digunakan untuk menentukan kekuatan atau kelemahan dari argumen-argumen. Dengan mengaplikasikan keterampilan evaluasi, maka individu dapat menilai kualitas analisis, interpretasi, penjelasan, inferensial, pilihan, opini, kepercayaan, ide, proposal, dan keputusan. Keterampilan menjelaskan dapat mendukung proses evaluasi yang berkualitas tinggi dengan menyiapkan bukti, alasan-alasan, metode, kriteria, atau asumsi di belakang tuntutan yang dibuat dan kesimpulan yang dicapai (Insight Assessment, 2019).

Hasil pada item induksi menunjukkan perbedaan dengan item-item yang lainnya, di mana mahasiswa yang memiliki critical thinking induksi pada tingkat sedang di kelompok kontrol lebih banyak daripada di kelompok intervensi. Sebaliknya, sisa mahasiswa, baik pada kelompok intervensi maupun pada kelompok kontrol samasama berada di tingkat yang tidak dapat dimanifestasikan. Sehingga tingkat critical thinking induksi pada kelompok kontrol lebih baik daripada kelompok intervensi. Sedangkan pada item evaluasi, nilai critical thinking tingkat sedang lebih banyak di kelompok intervensi daripada kelompok kontrol. Sedangkan sisanya, baik kelompok intervensi maupun kelompok kontrol berada pada tingkat yang tidak dapat dimanifestasikan. Banyak dari item tes yang memaparkan beberapa situasi dan meminta mahasiswa untuk menentukan tindakan selanjutnya yang tepat untuk diberikan. Pada item ini diperlukan keterampilan evaluasi yang baik dari mahasiswa. Sebab dengan keterampilan evaluasi yang baik, mahasiswa dapat mempertimbangkan alasan dari sebuah tindakan dan dampaknya yang akan muncul.

Masih banyaknya mahasiswa baik dalam kelompok intervensi maupun kelompok kontrol yang berada di tahap yang tidak dapat dimanifestasikan untuk item induksi dan evaluasi, menandakan bahwa mahasiswa belum mampu mempertimbangkan dengan baik dampak-dampak yang akan muncul akibat dilakukannya suatu tindakan. Hal ini pun diduga karena mahasiswa belum memiliki kepercayaan diri dalam menentukan sebuah tindakan untuk diberikan sesuai dengan pertanyaan dalam item tes. Proses 
evaluasi merupakan salah satu proses penting dalam asuhan keperawatan. Mahasiswa keperawatan, dengan menggunakan Teori Bloom diminta untuk menggunakan pengetahuan yang telah dimilikinya dalam menganalisis dan menyintesis masalah agar dapat diatasi sesuai dengan teori dan mencapai hasil yang diharapkan. Saat inilah terjadi fase evaluasi dan induksi yang setara dengan tingkatan aplikasi dalam taksonomi Bloom (Miller, M.L., 2018).

Sedlak dan Doheny, 2014, dalam Maldonado. S., 2014 menyatakan bahwa mahasiswa keperawatan seringkali mengalami kesulitan dalam mengorganisasi pemikiran mereka dan menghubungkannya dengan konsep keperawatan, sesuai dengan definisi keterampilan induksi. Kondisi ini dapat dibantu dengan penggunaan concept mapping-vignette dalam mengarahkan mahasiswa melihat hubungan antara konsep dengan kasus yang sedang terjadi. Proses ini berlanjut dengan evaluasi, sebagaimana pernyataan Oermann, 1997 dalam Maldonado, S., 2014, bahwa mahasiswa keperawatan harus mampu melakukan pengkajian, merencanakan asuhan keperawatan, memberikan intervensi keperawatan pada pasien dan keluarganya, serta mengevaluasi keefektifan intervensi yang diberikan yang mana proses ini membutuhkan kemampuan critical thinking yang baik.

Alasan deduktif berubah sesuai dengan presisi yang dibuat individu atas dasar asumsi pemikirannya ketika akan membuat sebuah keputusan yang tidak boleh salah. Validitas deduktif bersifat logis dan kaku. Validitas deduktif tidak menyediakan tempat bagi ketidakpastian, kecuali ada sesuatu yang mengubah arti sebuah kata atau tata bahasa dari sebuah bahasa. Sehingga Pengambilan keputusan yang didefinisikan sebagai konteks dalam mengatur, mengoperasikan suatu kondisi, kepercayaan terhadap nilai, kebijakan, prinsip, prosedur, dan terminologi yang akan menentukan hasil tergantung pada keterampilan deduktif yang kuat (Insight Assessment, 2019). Disamping itu, keterampilan inferensial atau menyimpulkan memampukan seseorang untuk menggambar kesimpulan dari berbagai alasan dan bukti. Inferensial digunakan ketika seseorang menawarkan saran pemikiran dan hipotesis. Keterampilan inferensial mengidentifikasikan kebutuhan atau konsekuensi yang sangat mungkin terjadi dari fakta-fakta dan kondisi yang ada. Simpulan, hipotesis, rekomendasi, atau keputusan yang didasarkan pada analisis yang salah, informasi yang salah, data yang buruk, atau evaluasi yang bias dapat membuat kesalahan walaupun mereka telah memiliki keterampilan inferensial/menyimpulkan yang sangat baik (Insight Assessment, 2019).

Bila dilihat dari hasil penelitian yang menunjukkan bahwa mayoritas mahasiswa baik dari kelompok intervensi maupun dari kelompok kontrol masih berada di tingkat tidak dapat dimanifestasikan, menandakan bahwa mahasiswa belum memiliki validitas deduktif yang kuat terutama ketika mengambil keputusan dari itemitem pertanyaan yang diberikan dalam tes. Sedangkan dari hasil inferensial, mayoritas mahasiswa baik dari kelompok intervensi maupun dari kelompok kontrol masih berada di tahap sedang, menandakan bahwa mahasiswa belum mampu menggabungkan antara ilmu-ilmu yang telah mereka dapatkan sebelumnya, yaitu ilmu konsep dasar keperawatan, ilmu keperawatan dasar, patofisiologi dan fisiologi, ke dalam ilmu keperawatan anak. Hasil ini bertolak belakang dengan penelitian sebelumnya (Aein, F., Aliakbari, F., 2017) yang menunjukkan bahwa melalui concept mapping keterampilan inferensial dan deduksi pada kelompok eksperimen memiliki nilai lebih tinggi secara signifikan daripada kelompok kontrol.

Keterampilan inferensial memampukan individu untuk menggambar kesimpulan berdasarkan alasan-alasan dan bukti-bukti yang ada. Kemampuan ini bergantung pada keterampulan deduktifnya. Ketika membuat concept map, mahasiswa perlu untuk menggambar kesimpulan secara logis berdasarkan pengetahuan yang mereka miliki sebelumnya atau premise yang mereka pelajari melalui proses inferensial yang dilalui menggunakan vignette, seperti mengidentifikasi konsep utama, menentukan 
hubungan antara konsep-konsep dengan membuat garis penghubung sebelum akhirnya menentukan kesimpulan. Sehingga, concept mapping membantu mahasiswa untuk menciptakan visualisasi mereka sendiri terhadap keseluruhan aspel dari data-data klinis pasien, pemeriksaan fisik, proses penyakit dan hubungan antara informasi-informasi ini. Proses ini memfasilitasi keterampilan critical thinking mahasiswa (Aein, F., Aliakbari, F., 2017).

Untuk mencapai tahapan ini diperlukan asimilasi dari konsep yang baru dengan konsep yang lama yang sebelumnya telah dipelajari oleh mahasiswa. Secginli, Erdogan, dan Monsen, 2013, dalam Miller, M., 2018, menjelaskan bahwa critical thinking merupakan level pemikiran yang tinggi, mahasiswa diminta untuk mengaji data, memikirkan asumsi, dan menyimpulkan ketika menentukan keputusan. Mahasiswa harus mampu mengaji kondisi pasien, menentukan perubahan data-data normal, dan menghubungkan perubahan nilai laboratorium dengan efek samping pengobatan dan proses penyakit. Pada tahap ini diperlukan kemampuan inferensial mahasiswa sebagai bagian dari critical thinking didasarkan pada hasil pengajian mahasiswa.

\section{Pengaruh Pendekatan Concept Mapping- Vignette Terhadap Stimulasi Critical Thinking Mahasiswa Pada Mata Kuliah Keperawatan Anak}

Secara umum tidak ada pengaruh pendekatan concept mapping-vignette terhadap stimulasi critical thinking mahasiswa pada mata kuliah Keperawatan Anak. Namun bila dilihat secara spesifik dari setiap item critical thinking, terlihat bila responden pada kelompok intervensi memiliki nilai critical thinking yang relatif lebih tinggi dibandingkan dengan responden pada kelompok kontrol. Item-item critical thinking pada kelompok intervensi yang memiliki nilai lebih tinggi dari kelompok kontrol yaitu analisis, inferensial, evaluasi, dan deduksi. Sedangkan hanya item induksi, yang mana nilai pada kelompok intervensi lebih rendah dari kelompok kontrol. Dengan demikian dapat disimpulkan bahwa pendekatan concept mapping-vignette dapat menstimulasi critical thinking mahasiswa pada mata kuliah Keperawatan Anak walaupun tidak terlalu signifikan. Beberapa hasil penelitian sebelumnya menyebutkan bahwa adanya efek jangka pendek yang positif dari penerapan concept mapping terhadap critical thinking mahasiswa baik di dalam kelas maupun di klinik (Lee, W., Chiang, CH., Lee, M.L., 2013 dalam Aein, F., Aliakbari, F., 2017). Namun terdapat penelitian dari Wheeler dan Collin, 2003, dalam Aein, F., Aliakbari, F., 2017, yang menyatakan bahwa nilai pada kelompok intervensi yang diberikan strategi concept mapping lebih tinggi dari kelompok kontrol pada item analisis dan evaluasi tetapi tidak memiliki perbedaan yang signifikan antara kedua kelompok tersebut.

Hasil penelitian ini mengindikasikan bahwa pendidik/dosen harus memberikan perhatian lebih untuk terus menggali kemampuan critical thinking mahasiswa. Walaupun hasil penelitian tidak menunjukkan signifikansi namun strategi pembelajaran concept mapping-vignette dapat meningkatkan kemampuan critical thinking mahasiswa. Rendahnya nilai critical thinking pada mahasiswa dapat disebabkan karena metode concept mapping-vignette ini baru pertama kali diaplikasikan dalam pembelajaran di kelas, sehingga mahasiswa maupun dosen yang memberikan pengajaran belum memiliki pengalaman sebelumnya. Kondisi ini sesuai dengan paparan yang diungkapkan oleh $\mathrm{Li}$, Shasha, Ye, Xuchun, dan Chen, Wenting, 2019, bahwa vignette yang digunakan dalam pembelajaran tidak hanya terkait dengan proses penyakit saja, melainkan juga berhubungan dengan pengalaman emosional individu dalam merawat pasien dan hal ini dapat mempengaruhi kepercayaan diri mahasiswa. Sehingga dalam penyampaiannya diperlukan penguasaan yang baik dari dosen dalam mempertahankan interaksi yang baik antara dosen dan mahasiswa, dosen dan mahasiswa perlu diperkenalkan dan dibiasakan menggunakan concept mappine-vignette dalam pembelajaran keseharian baik di kelas maupun di klinik. 
Zhang, 2016 dalam Li, Shasha, Ye, Xuchun, dan Chen, Wenting, 2019, mengungkapkan bahwa untuk meningkatkan keterampilan critical thinking mahasiswa keperawatan diperlukan tidak hanya satu strategi pembelajaran, namun memerlukan multidimensional strategi pembelajaran untuk mengembangkan kemampuan asimilasi pengetahuan mahasiswa dari berbagai sumber pembelajaran. Gao, 2016 dalam Li, Shasha, Ye, Xuchun, dan Chen, Wenting, 2019, juga menyebutkan bahwa perlu adanya pengulangan kegiatan belajar dengan menggunakan concept mapping-vignette agar mahasiswa dapat memiliki visualisasi yang nyata terkait dengan kasus yang sedang dibahas. Hubungan antara konsep dapat lebih jelas terlihat dengan menggunakan tanda panah, sehingga mahasiswa dapat mengasimilasi beberapa konsep baru ke dalam kemampuan kognitif mereka. Bila kondisi ini telah tercapai maka akan timbul pembelajaran yang bermakna. Selain itu, concept-map juga memberikan visualisasi konkrit dari aspek fisiologis, patologis, dan psikologis, serta interaksi-interaksinya daripada hanya menggunakan kata-kata, frase atau ide-ide (Aein, F., Aliakbari, F., 2017).

\section{SIMPULAN}

Secara umum tidak ada pengaruh pendekatan concept mapping-vignette terhadap

\section{DAFTAR PUSTAKA}

Aein, F., \& Aliakbari, F. (2017). Effectiveness of Concept Mapping and Traditional Linear Nursing Care Plans on Critical Thinking Skills in Clinical Pediatric Nursing Course. Journal of Education and Health Promotion, 6(3), 1-6.

AIPNI. (2015). Kurikulum Pendidikan Ners. Cimahi: STIKes Budi Luhur.

Akademik, B. A. (2018). Laporan Akademik Prodi Pendidikan Ners. Cimahi: STIKes Budi Luhur.

Aliarosa, W. (2018). Nursing Students' Skills Level of Promote Safety, Physiology Integrity, Psychosocial Integrity, and Health Promotion in Pediatric Care in a Selected stimulasi critical thinking mahasiswa pada mata kuliah Keperawatan Anak. Tetapi bila dilihat secara frekuensi dari setiap item critical thinking, responden pada kelompok intervensi memiliki nilai critical thinking yang sedikit lebih tinggi dibandingkan dengan responden pada kelompok kontrol. Khususnya pada item analisis, inferensial, evaluasi, dan deduksi. Sedangkan pada item induksi, nilai pada kelompok intervensi lebih rendah dari kelompok kontrol. Sehingga pendekatan concept mapping-vignette dapat menstimulasi critical thinking mahasiswa pada mata kuliah Keperawatan Anak walaupun tidak terlalu signifikan.

Oleh karena itu, pendekatan ini dapat dipakai dalam strategi pembelajaran berikutnya khususnya dalam mata kuliah Keperawatan Anak, dan juga dapat diterapkan untuk mata kuliah keperawatan klinis lainnya. Hasil penelitian ini tidak dapat digeneralisasikan dan dibutuhkan penelitian lebih lanjut dengan menambah jumlah responden serta menggunakan desain penelitian pre-test dan post-test dengan kelompok kontrol.

\section{UCAPAN TERIMA KASIH}

Ucapan terimakasih kepada Kemenristek Dikti yang telah mendanai penelitian ini pada Skema Kompetitif Nasional Penelitian Dosen Pemula tahun 2018-2019.

Health Institute in Indonesia. Health Notion Journal, 2(8), 862-873.

Aliarosa, W. (2019). Modul Keperawatan Anak. Cimahi: STIKes Budi Luhur.

Assessment, I. (2019). Complimentary User Manual Excerpts California Critical Thinking Skills Test. San Jose: The California Academic Press.

Bravo, K., \& Pozehl, B. (2016). Revision and Psychometric Testing of the Safe Administration of Medication Scale. Journal of Nursing Measurement, 24(1), 147-165.

Broadhead, J. (2016). The Impact of HumanitiesBased Teaching and Learning Strategies on Critical Thinking and Clinical Reasoning Development Among BSN Students. Minnesota: Capella University. 
Carbogim, F., Barbosa, A., \& Oliviera, L. (2018). Educational Intervention to Improve Critical Thinking for Undergraduate Nursing Students: A Randomized Clinical Trial. Nurse Education in Practice Journal, 33, 121-126.

Gamble, A. (2017). Simulation in Undergraduate Paediatric Nursing Curriculum: Evaluation of a Complex 'Ward for a Day' Education Program. Nurse Education in Practice Journal, 23, 40-47.

Li, S., Ye, X., \& Chen, W. (2019). Practice and Effectiveness of "Nursing Case-Based Learning" Course on Nursing Student's Critical Thinking Ability: A Comparative Study. Nurse Education on Practice Journal, 36, 91-96.

Maldonado, S. (2014). Effects of Concept Mapping on the Critical Thinking Skills of Baccalaureate Nursing Students. New York: Walden University.

McCormick, K. (2014). The Effect of Learning Styles, Critical Thinking Disposition, and Critical Thinking on Clinical Judgement in Senior Baccalaureate Nursing Students During Human Patient Simulation. Lousiana:
The School of Nursing southern University and A\&M College.

Miller, M. (2018). High Fidelity Nursing Using Electronic Health Record Systems: Impact on Critical Thinking in Nursing Practice. Georgia: Graduate School, Valdosta State University.

Piryani, R., \& Piryani, S. (2019). Clinical VignetteBased Interactive Discussion Sessions: Feedback from Residents. Advances in Medical Education and Practice, 10, 829833.

Riede, P. (2015). Critical Thinking Skills of Beginning Associate Degree Nursing Students: A Study of Relationship Between Critical Thinking Skills And Nursing Program Succes. Proquest.

Zarifsanaiey, N., Amini, M., \& Saadat, F. (2016). A Comparison of Educational Strategies for Acquisition of Nursing Student's Performance and Critical Thinking: Simulation-Based Training vs. Integrated Training (Simulation and Critical Thinking Strategies). BMC Medical Educational Journal, 16(294), 1-7. 